\title{
Influence of selected biogenic amines on development and demographic parameters of a temperate population of Cinara (Cupressobium) cupressi (Hemiptera, Aphididae)
}

\author{
Karina Wieczorek ${ }^{1}$ (D) P Piotr Świątek ${ }^{1}$ (D) $\cdot$ Roma Durak $^{2}$ (D)
}

Received: 5 August 2020 / Accepted: 7 May 2021 / Published online: 19 May 2021

(c) The Author(s) 2021

\begin{abstract}
Cinara (Cupressobium) cupressi, the cypress aphid, is a serious pest of Cupressus spp. and other Cupressaceae, considered to be one of the world's 100 worst invasive alien species. The potential influence of selected biogenic amines (tryptamine, tyramine, putrescine, and cadaverine) on development and demographic parameters of a temperate population of the cypress aphid was investigated under laboratory conditions. Within parthenogenetic generations, the use of biogenic amines resulted in a significant reduction in the total fecundity and the average daily fecundity both in the fundatrix (F0) and the fundatrigeniae (F1), whereas this influence in the F5 generation was insignificant. In all parthenogenetic generations treated with amines, the dissected female abdomen contained a greater number of mature embryos compared to control samples. Cadaverine caused marked changes in the body length of all viviparous generations studied and a significant reduction in the number of developing embryos, compared to the control sample. The use of biogenic amines did not significantly affect the number of eggs produced by oviparous females but had an impact on their lifespan. Our results indicate that biogenic amines application may disrupt feeding behavior and thus leads to reduced fecundity, consistent with the observation of reduced embryo production. Consequently, bioamines can be used as an alternative agents to control this important pest species.
\end{abstract}

Keywords Cadaverine $\cdot$ Cypress aphid $\cdot$ Fecundity $\cdot$ Pest management $\cdot$ Polyamines $\cdot$ Reproduction

\section{Introduction}

Cinara (Cupressobium) cupressi (Buckton, 1881) (Hemiptera, Aphididae), the cypress aphid, is a serious pest of Cupressus spp. and other Cupressaceae (Austrocedrus, Callitris, Chamaecyparis, Fitzroya, Juniperus, Thuja, Widdringtonia, the hybrid Cupressocyparis), presently worldwide distributed (Blackman and Eastop 2020). It is the only aphid species included in the list of the world's 100 worst invasive species (Lowe et al. 2000), seriously damaging commercial and ornamental plantings of coniferous trees around the globe, able to feed on native or endemic conifers

Handling Editor: Dagmar Voigt.

Karina Wieczorek

karina.wieczorek@us.edu.pl

1 Faculty of Natural Sciences, University of Silesia in Katowice, Bankowa 9, 40-007 Katowice, Poland

2 Department of Experimental Biology and Chemistry, University of Rzeszów, Pigonia 1, 35-310 Rzeszów, Poland
(Ciesla 1991; Montalva et al. 2010; Alford 2012; Demeke 2018). The species is also easily transported on planting stock on imported plant material (Remaudière and Binazzi 2003).

Currently, it is accepted that $C$. (C.) cupressi is a complex of several morphologically similar species. The CABI Invasive Species Compendium (2020) includes them all under $C$. $(C$.) cupressi "sensu lato" (in the broadest sense). According to Remaudière and Binazzi (2003), Blackman and Eastop (2020), and Favret (2020), its African population distinguished as C. cupressivora Watson and Voegtlin 1999 is a synonym of $C .(C$.) cupressi.

In temperate climates it is a monoecious, holocyclic species with the life cycle consisting of nine to twelve parthenogenetic generations (Mustafa 1987; Ciesla 1991; Binazzi 1978) followed by the sexual generation (Durak et al. 2007; Durak and Durak 2015). In warmer climates, the species reproduce asexually by parthenogenesis all year round (Kairo and Murphy 1999). The aphids feed on the bark of small twigs and branches in the inner and lower parts of the main canopy. The parthenogenetic generations are usually 
numerous and dense colonies, with up to $60-80$ aphids per $10 \mathrm{~cm}$ of branch which develop in shady locations in the lower parts of the canopy (Ciesla 1991; Durak et al. 2007). Generally, the overall effect on the host plants ranges from partial damage to eventual death of the entire tree, especially in the warmer regions of the world. The species is also a vector of Cyprus canker (caused by the fungi Seiridium cardinale and Lepteutypa cupressi), which has devastated some cypress trees populations. Moreover, feeding aphids produce large amounts of honeydew, which promotes the growth of sooty mold, negatively affecting plant growth (Dransfield and Brightwell 2020).

In temperate climates, during spring the cypress aphid sucks the sap from twigs, causing yellowing to browning of the foliage on the affected twig. Later, initial heavy infestation of small twigs and branches in the inner and lower canopy, during heat and drought, causes progressive dieback from the outer edges of the canopy, with the foliage turning reddish-brown. By late summer many of these are brown and dead. As the branch tips die, the aphids move inwards, continuing to feed on the living tissue. On clipped hedges the dieback can be quite pronounced, with the lower parts often more severely affected than the top because the aphids move down to the ground level, seeking protection from the summer heat (RHS 2004; FAO 2009; GISD 2020; CABI 2020). Size dynamics of the cypress aphid showed two peaks, the first in the middle of May (parthenogenetic generation) and the second one at the end of September and in the middle of October (sexual generation). Beginning in the middle of October oviparous females laid from two to seven eggs, which overwinter (Durak et al. 2007).

Various hymenopteran endoparasitoids have been used for the biological control of $C$. (C.) cupressi, but with varying levels of success (Mills 1990; Chilima 1995; Day et al. 2003; Kairo and Murphy 2005; Alleck et al. 2006; González et al. 2008; Missanjo and Kamanga-Thole 2015). Other natural enemies such as Coccinellidae or Chrysomelidae showed some degree of control, but they were not satisfactory in reducing the aphid populations (Montalva et al. 2013). Similarly, a wide variety of pesticides and various modes of their application have been tested against these aphids. In addition to selective aphicides, such as Ekatin and Pirimor, organic sprays, i.e., natural pyrethrum, fatty acids or plant oils, can enable control of these aphids (RHS 2004).

Within natural pest control methods, using biogenic amines (BAs) are a promising alternative to chemical control. Biogenic amines constitute a group of basic nitrogen compounds that are important to cell metabolism and viability (Pereira et al. 2018). They can be naturally synthetized by certain plants and play important roles in diverse plant growth and developmental processes as well as responses to environmental biotic and abiotic stresses (Chen et al. 2019). It has been shown in previous studies that plants develop defensive molecular mechanisms in their response to infestation by herbivorous insects, including aphids. These responses may be connected in particular with the induction of the biosynthesis of polyamines and aromatic monoamines, which can limit feeding and survival of herbivorous insects, in particular aphids (Sempruch et al. 2010, 2011, 2013, 2016). Polyamines (PAs) are small polycationic molecules bearing amino groups, synthesized mostly from amino acids with the participation of amino acid decarboxylases. Diamine putrescine (Put), triamine spermidine (Spd), and tetraamine spermine ( $\mathrm{Spm})$ are the most common PAs found in higher organisms. The diamine cadaverine (Cad) is synthesized through the decarboxylation of lysine. Aromatic amines include tryptamine (Tryp), formed from the decarboxylation of tryptophan by L-aromatic amino acid decarboxylase, and tyramine (Tyr), formed by decarboxylation of tyrosine (Hennion et al. 2016).

Knowledge of the aphid reproductive strategy and the possibility of its regulation using natural plant biomolecules is the basis for developing effective ways to prevent and combat these pests and the diseases that are transmitted by viruses. Thus, in the present study, the effects of common plant BAs on the cypress aphid were studied under controlled conditions. For our research, we used a holocyclic population found in Poland, which was a good reason to study the effect of selected amines on parthenogenetic and sexual generations, representing the full life cycle of this species. In particular, using such compounds as tyramine (aromatic monoamine), tryptamine (heterocyclic diamine), putrescine and cadaverine (aliphatic diamines), the influence of these BAs on development and demographic parameters of the population of the cypress aphid was tested, identifying alternative agents to control this important pest species.

\section{Material and methods}

\section{Plants, aphids, and chemicals}

Two-year-old seedlings of juniper Juniperus scopulorum plants were used in the experiments. The plants were grown in plastic pots $(8.0 \times 9.5 \mathrm{~cm})$ with universal horticultural soil and watered regularly. Before establishing the experiment, seedlings were grown in a breeding room for two weeks at $20{ }^{\circ} \mathrm{C}$ and watered regularly.

We used different generations of Cinara (Cupressobium) cupressi (Buckton) - viviparous: fundatrix (stem mother, F0), fundatrigenia ( $\mathrm{F} 1$ - parthenogenetic spring generation), F5 (parthenogenetic summer generation), and oviparous female (sexual generation) (Fig. 1a-d). Parthenogenetic and sexual populations that were used in the experiments came from cultures grown at the University of Rzeszów, Poland. Aphids were reared on J. scopulorum under controlled 
Fig. 1 Viviparous and oviparous generations of $C$. (C.) cupressi a fundatrix (F0); $\mathbf{b}$ fundatrigenia (F1); c summer viviparous females (F5); d wingless oviparous females and winged male
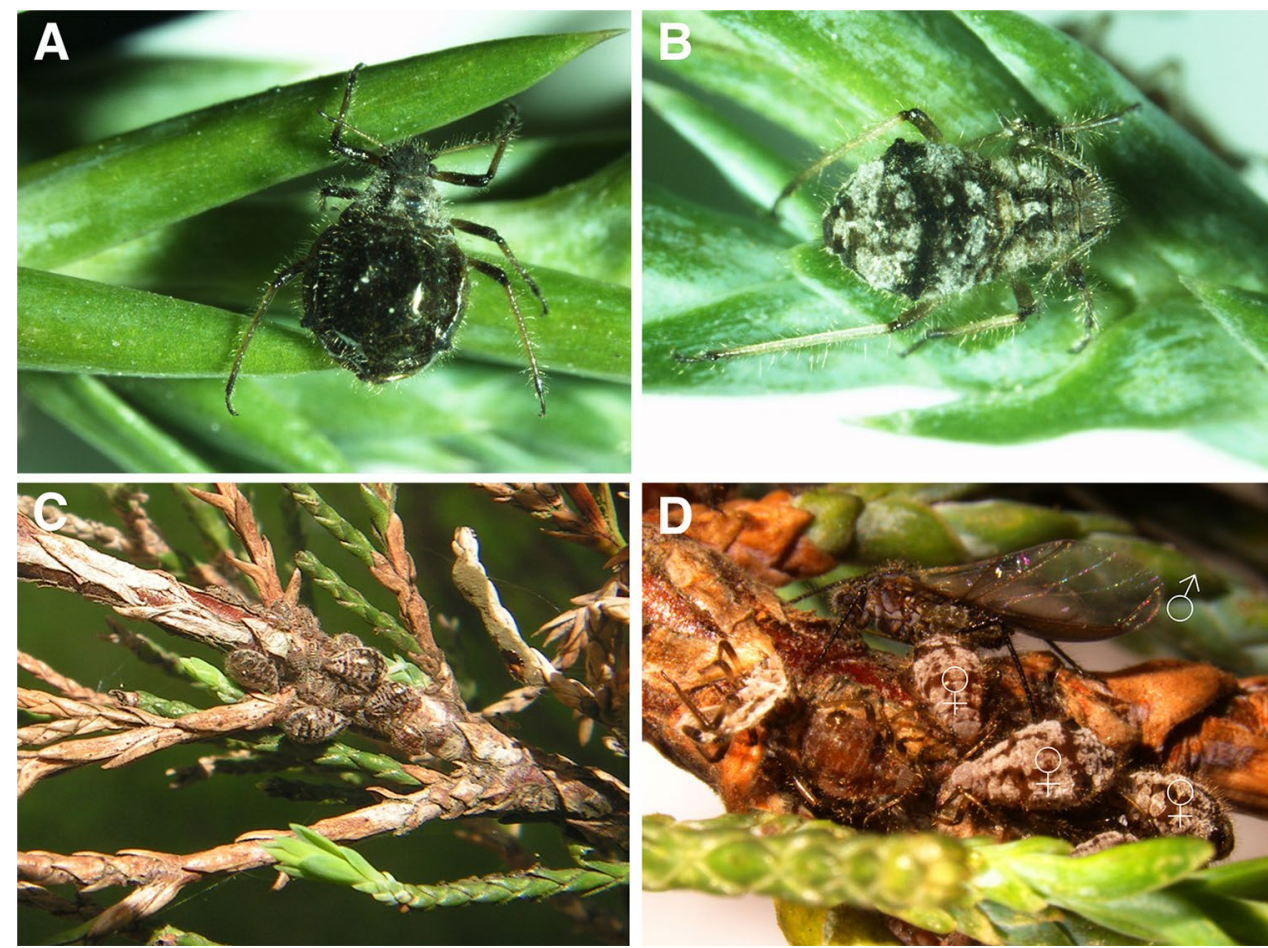

conditions in a climatic chamber (MLR-351H; Sanyo Corp., Japan). During all experiments, we maintained the same conditions of temperature $20{ }^{\circ} \mathrm{C}$, humidity $60 \% \pm 5 \%$, nutrients and light sources $\mathrm{L}: \mathrm{D}=16: 8$, for plants which were used in the experiments carried out in a culture room (breeding room).

Individual amines (cadaverine, putrescine, tryptamine, and tyramine) were purchased from Sigma-Aldrich, (EC No. C8561, P5780, 200-510-05 and T2879, respectively).

\section{Effect of amines on development and demographic parameters of the parthenogenetic generation F1 of C. (C.) cupressi}

The adult apterous females of the spring generation (F1) of $C$. (C.) cupressi were placed individually on $J$. scopulorum and sprayed with $10 \mathrm{~cm}^{3}$ of $10 \mathrm{mM}$ aqueous solutions of cadaverine, putrescine, tryptamine, and tyramine or redistilled water (control) ( $n=25$ for each amine and control). The seedlings were next dried at room temperature for $30 \mathrm{~min}$. After $24 \mathrm{~h}$, one nymph remained on each single plant, and the other offspring and adults were removed. The experiment was run in 15 independent replicates for each treatment. The aphid pre-reproductive period (time from birth until maturity in days) and daily fecundity were estimated (Leszczyński et al. 1989). The intrinsic rate of natural increase $\left(r_{\mathrm{m}}\right)$ and mean time of generation development $(T)$ were calculated using the following equations after Wyatt and White (1977): $r_{\mathrm{m}}=0.738 \frac{\ln M d}{d}$

$T=\frac{d}{0.738}$

where $d$ is the length of pre-reproductive period, $M d$ the number of larvae born during the reproduction period, which equals the $d$ period, 0.738 the correction constant.

\section{Effect of amines on the total fecundity and average daily fecundity of parthenogenetic generations F0, $F 1$, and $F 5$ of $C$. (C.) cupressi}

The adult apterous females of $C$. (C.) cupressi, representing various parthenogenetic generations-fundatrix (F0), spring generation (F1), and summer generation (F5) were placed on J. scopulorum plants. The aphids were placed separately, five individuals per plant ( $n=25$ for each generation and for each amine). The plants with the aphids were sprayed with $10 \mathrm{~cm}^{3}$ of $10 \mathrm{mM}$ aqueous solutions of amines: cadaverine, putrescine, tryptamine, and tyramine or redistilled water (control). We monitored the number of larvae each day and removed the newborn. The experiment continued for 8 days. Based on the observations made, total fecundity and average daily fecundity were determined. 


\section{Effect of amines on the number and size of embryos developed in the parthenogenetic generations F0, $F 1$, and $F 5$ of $C$. (C.) cupressi}

After the end of each experiment, females from each generation tested were collected directly from their host plants and placed into Eppendorf tubes containing 2.5\% glutaraldehyde for further morphological investigations. All embryos were dissected from whole insects ( $n=5$ for each generation and for each amine), treated with tris-buffered saline and stored in glycerol, examined using a Nikon SMZ 25 stereoscopic microscope, photographed using a Nikon DS-Fi2 camera and measured with NIS-Elements D 4.50.00 64-Bit. The length of embryos and the length of the largest mature embryo were measured for each dissected female. The total number of embryos and the ratio of the number of mature to immature embryos were recorded. Embryos were considered as mature if the eyes of the embryo were pigmented. In addition, before dissection the size of all viviparous females from the control aphids and those treated with amines were measured.

\section{Effect of amines on structures of the reproductive system and survival of oviparous females of $C$. (C.) cupressi}

The adult apterous oviparous females of $C$. (C.) cupressi were placed on $J$. scopulorum plants. The females were sprayed with $10 \mathrm{~cm}^{3}$ of $10 \mathrm{mM}$ aqueous solutions of amines: putrescine, cadaverine, tyramine, tryptamine, or with redistilled water (control) $(n=25$ for each amine and control). We monitored the survival of aphids each day. After the end of each experiment, oviparous females were collected directly from their host plants and placed into Eppendorf tubes containing $2.5 \%$ glutaraldehyde for further morphological investigations. The reproductive system was dissected from whole insects ( $n=5$ for each amine and control), treated with tris-buffered saline and stored in glycerol, examined using a Nikon SMZ 25 stereoscopic microscope, photographed using a Nikon DS-Fi2 camera and its structures were measured with NIS-Elements D 4.50.00 64-Bit. In addition, before dissection, all oviparous females from the control and those treated with amines were measured.

\section{Statistical analyses}

Data were tested for normality and homogeneity of variances. Two-way analysis of variance (ANOVA), with amines and generation as fixed factors, was used to test the differences between the total fecundity, daily fecundity, morphological and developmental characteristics of females, and post hoc comparisons using Duncan multiple test range. All data are presented as means with standard error values (mean $\pm \mathrm{SE}$ ). To compare the survival distribution curves of populations of aphids after application of amines, the log-rank test $\mathrm{chi}^{2}$ was applied. Statistical analyses were performed using the statistical program Statistica (data analysis software system), version 13 (TIBCO Software Inc. 2017, http://statistica.io.) and PAST (PAleontological STatistic version 3.25; Hammer et al. 2001).

\section{Results}

\section{Effects of amines on development and demographic parameters of the parthenogenetic generation $F 1$ of $C$. (C.) cupressi}

The applied amines caused changes in the development, and demographic parameters of the aphid population studied. Tyramine shortened the pre-reproduction period, while cadaverine extended this period in comparison to the control population (Table 1). Tryptamine and putrescine did not affect the length of the pre-reproduction period. The calculated demographic parameters of the aphid population decreased after using the amines in comparison to the control. The intrinsic rate of increase $\left(r_{\mathrm{m}}\right)$ reached a minimum value $(0.01)$ in the population treated with tyramine and putrescine, and a maximum in the population treated with cadaverine and tryptamine (0.02). The generation time $(T)$ was the longest in the population treated with tyramine and putrescine (21.43 days, 21.54 days, respectively), while the shortest was in the population treated with tryptamine (12.44 days).
Table 1 Influence of selected biogenic amines (10 $\mathrm{mM}$ concentration) on population parameters (arithmetic mean \pm standard error) of $C$. (C.) cupressi

\begin{tabular}{llllll}
\hline Parameters & \multicolumn{2}{l}{ Biogenic amines } \\
\cline { 2 - 6 } & Control & Tryptamine & Tyramine & Putrescine & Cadaverine \\
\hline Pre-reproductive period (days) & $12.00 \pm 0.0$ & $12.0 \pm 0.0$ & $11.0 \pm 0.0$ & $12.0 \pm 0.0$ & $14.00 \pm 0.0$ \\
Mean generation time $(T)($ days $)$ & 15.24 & 12.44 & 21.43 & 21.54 & 20.97 \\
Intrinsic rate of increase $\left(r_{\mathrm{m}}\right)$ & 0.03 & 0.02 & 0.01 & 0.01 & 0.02 \\
\hline
\end{tabular}




\section{Effects of amines on total fecundity and average daily fecundity of parthenogenetic generations of $C$. (C.) cupressi}

The main effect of amines on total fecundity of aphids was significant (two-way ANOVA $F_{(4,105)}=39.85, p<0.001$ ). Moreover, generation had a significant effect on total fecundity (two-way ANOVA $F_{(2,105)}=100.79, p<0.001$ ). There was also a significant interaction effect between amines and generation on total fecundity (two-way ANOVA $F_{(8,105)}=13.55, p<0.001$ ) (Supplementary Information Table S1). Our research indicated that the use of amines resulted in a significant reduction in the total fecundity of the fundatrix (F0) and spring (F1) generations (Fig. 2a). The decrease in fecundity of females of the summer generation (F5) was not statistically significant.

Fundatrices (F0, control) gave birth to an average of 29.4 larvae per female. After using tryptamine, total female fecundity decreased to around 17.2 larvae per female; the use of cadaverine had a similar effect. Tyramine and putrescine reduced the fecundity of the fundatrices by half (Fig. 2a).

The females of the spring generation of $C$. (C.) cupressi (F1, control) gave birth to an average 20.7 larvae. Tryptamine and tyramine reduced female fecundity by half (respectively, 10.5 and 10.9 larvae per female). Putrescine and cadaverine lowered total fecundity of females to 13.7 and 16.7 larvae per female, respectively (Fig. 2a).

The females of the summer generation of $C$. $(C$.) cupressi (F5, control) gave birth to an average of 9.8 larvae. After using bioamines, any significant statistic differences in the females fecundity have been observed (Fig. 2a).

Putrescine and tyramine showed the strongest influence on total fecundity of fundatrices (F0) and reduced the number of larvae by about $51 \%$ and $46 \%$, respectively. On the other hand, tryptamine and tyramine, which reduced the number of larvae by about $49 \%$ and $47 \%$, had the strongest impact on the reduction of the total fecundity of F1 females.

Amines had a significant effect on average daily fecundity of females (two-way ANOVA $F_{(4,105)}=37.98, p<0.001$ ), as did generation (two-way ANOVA $F_{(2,105)}=107.17$, $p<0.001)$. We also found a significant interaction effect between amines and generation on average daily fecundity of females (two-way ANOVA $F_{(8,105)}=15.35, p<0.001$ ) (Supplementary Information Table S1). We observed a significant reduction in the daily fecundity of fundatrices and females of F1 generations, while the reduction in fecundity of F5 females was not significant (Fig. 2b).
Fig. 2 Influence of selected biogenic amines on total fecundity (a) and average daily fecundity (b) of $C$. (C.) cupressi generations: fundatrices (F0), fundatrigeniae, parthenogenetic spring generation (F1), parthenogenetic summer generation (F5) ( $n=25$ for each generation and each amine and control). Values marked with different letters differ significantly at $p<0.05$ based on the Duncan test
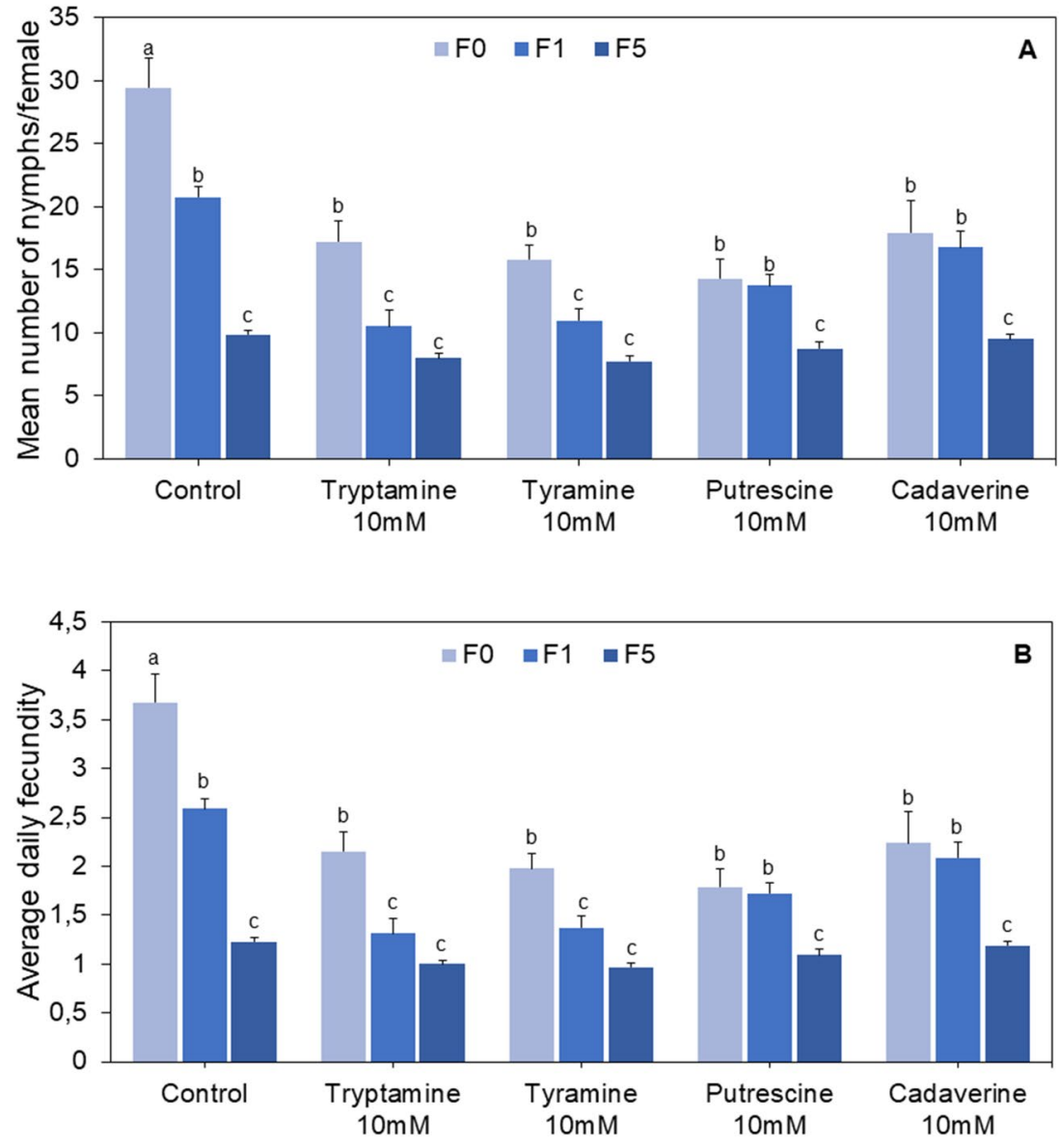
Fundatrices (F0, control) daily gave birth to an average of 3.6 larvae per female. Putrescine and tyramine reduced female daily fecundity by half (respectively, 1.7 and 1.9 larvae per female), while tryptamine and cadaverine had less effect on the daily fecundity (respectively, 2.1 and 2.2 larvae per female) (Fig. 2b).

The females of the spring generation of $C$. (C.) cupressi (F1, control) daily gave birth to an average of 2.5 larvae. Tryptamine and tyramine reduced female daily fecundity by half, whereas putrescine and cadaverine lowered daily fecundity of females to 1.7 and 2.0 larvae per female, respectively (Fig. 2b).

The females of the summer generation of $C$. $(C$.) cupressi (F5, control) daily gave birth to an average of 1.2 larvae. After applying biogenic amines, daily female fecundity decreased only slightly (Fig. 2b).

After applying putrescine and tyramine daily fecundity of fundatrices (F0) and parthenogenetic females of F1 generation decreased by over $45 \%$.

\section{Effect of amines on number and size of embryos developed in the parthenogenetic generations Fo, $\mathrm{F} 1, \mathrm{~F} 5$ of $C$. (C.) cupressi}

The body size, number, and size of embryos of parthenogenetic females were dependent on generation and amine used (Supplementary Information Table S2). Fundatrices (F0) not sprayed with biogenic amines (control) were significantly larger than females of this generation treated with amines (Table 2). The stem mothers were the smallest after using tryptamine or cadaverine. Tyramine and putrescine had a weaker effect on the body size of the fundatrices, but still, these females were clearly smaller than the individuals from the control sample (Fig. 3a). The use of biogenic amines also affected the number of embryos (Table 2). All fundatrices treated with amines developed half as many embryos as compared to females from the control sample. The developing embryos were similar in size both in controls and in females treated with biogenic amines. However, stem mothers who were sprayed with amines usually had two to four embryos significantly larger than other ones. The lowest number of embryos was observed in the fundatrices treated with cadaverine (Table 2).
Table 2 Body length (in mm), number, and size of embryos of viviparous generations ( $\mathrm{F} 0$ fundatrices, F1-fundatrigeniae, F5-summer viviparous females) and body length (in $\mathrm{mm}$ ), number, and size of eggs of oviparous generation of $C$. $(C$.) cupressi $(n=5)$ not sprayed and sprayed with selected biogenic amines

\begin{tabular}{|c|c|c|c|c|c|}
\hline \multirow[t]{2}{*}{ Parameters } & \multicolumn{5}{|c|}{ Biogenic amines } \\
\hline & Control & Tryptamine & Tyramine & Putrescine & Cadaverine \\
\hline \multicolumn{6}{|l|}{ F0 } \\
\hline Body length & $3.00-3.87$ & $2.08-2.69$ & $2.48-3.03$ & $2.18-3.01$ & $2.15-2.75$ \\
\hline Total embryo number & $27-30$ & $9-13$ & $2-12$ & $11-12$ & $5-7$ \\
\hline Embryo number & $12-15 / 15$ & $5-8 / 4-5$ & $2-10 / 0-2$ & $5-6 / 5-7$ & $3-4 / 2-3$ \\
\hline \multicolumn{6}{|l|}{ Mature/small } \\
\hline Embryo length & $0.81-1.34$ & $0.81-1.42$ & $0.81-1.38$ & $0.89-1.23$ & $0.94-1.10$ \\
\hline Mature/small & $0.35-0.51$ & $0.40-0.76$ & $0.36-0.68$ & $0.40-0.47$ & $0.31-0.62$ \\
\hline \multicolumn{6}{|l|}{$\mathrm{F} 1$} \\
\hline Body length & $2.05-3.20$ & $2.11-2.87$ & $1.98-2.67$ & $1.98-2.48$ & $2.0-2.43$ \\
\hline Total embryo number & $12-19$ & $8-15$ & $13-17$ & $12-14$ & $9-14$ \\
\hline Embryo number & $3-5 / 12-14$ & $4-5 / 4-10$ & $7-8 / 5-8$ & $6-8 / 5-7$ & $4-7 / 5-9$ \\
\hline \multicolumn{6}{|l|}{ Mature/small } \\
\hline Embryo length & $1.07-1.28$ & $1.07-1.29$ & $1.1-1.21$ & $0.93-1.24$ & $0.90-1.18$ \\
\hline Mature/small & $0.38-0.64$ & $0.45-0.78$ & $0.45-0.73$ & $0.33-0.80$ & $0.28-0.72$ \\
\hline \multicolumn{6}{|l|}{ F5 } \\
\hline Body length & $2.49-3.43$ & $2.05-2.45$ & $2.23-3.18$ & $2.01-2.78$ & $2.11-2.58$ \\
\hline Total embryo number & $6-8$ & 3 & $1-2$ & $1-2$ & $1-6$ \\
\hline Embryo number & $2-4 / 3-5$ & $3 / 1-2$ & $1-2 / 0$ & $1-2 / 0$ & $1 / 1-5$ \\
\hline \multicolumn{6}{|l|}{ Mature/small } \\
\hline Embryo length & $1.18-1.26$ & $1.08-1.40$ & $1.00-1.20$ & $1.12-1.16$ & $1.01-1.40$ \\
\hline Mature/small & $0.40-0.56$ & $0.34-0.80$ & & & $0.58-0.74$ \\
\hline \multicolumn{6}{|l|}{ Oviparous female } \\
\hline Body length & $2.70-3.31$ & $2.38-2.75$ & $1.87-2.33$ & $2.56-3.12$ & $2.77-3.21$ \\
\hline Number of eggs & $6-7$ & $6-7$ & $6-7$ & $6-7$ & $6-7$ \\
\hline Eggs length & $1.01-1.13$ & $1.05-1.17$ & $0.53-1.02$ & $0.86-1.17$ & $0.73-1.02$ \\
\hline
\end{tabular}




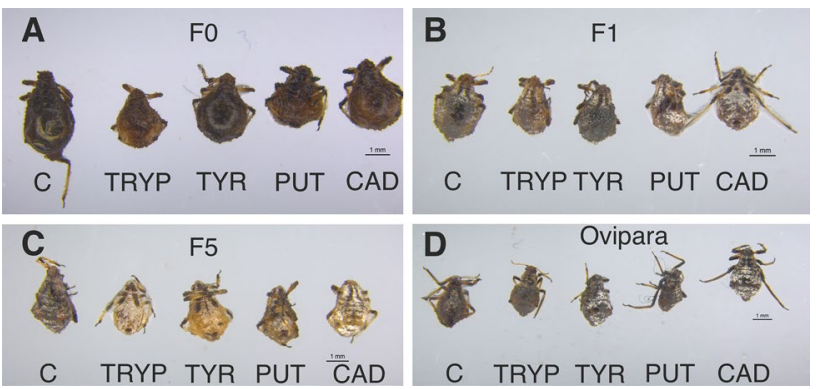

Fig. 3 Comparison of the body length of viviparous and oviparous generations of $C$. $(C$.) cupressi a fundatrices (F0); $\mathbf{b}$ fundatrigeniae (F1); c summer viviparous females (F5); d oviparous females not sprayed and sprayed with selected biogenic amines $(\mathrm{C}-$ control; TRYP-tryptamine; TYR-tyramine; PUT—-putrescine; CADcadaverine)

In the F1 generation, females feeding on plants sprayed with biogenic amines were smaller than females from the control sample (Table 2). However, the differences in size were not as visible as in the F0 generation (Fig. 3b). Similarly, the total number of embryos in the fundatrigeniae from the control sample was slightly higher than in individuals treated with amines (the lowest with tryptamine or cadaverine). The ratio of mature to immature embryos in females treated with amines was similar, whereas in females from the control group of immature embryos, there were two to three times more. The smallest mature embryos were in females of the F1 generation exposed to cadaverine (Table 2).

In the F5 generation, viviparous females treated with biogenic amines were smaller (the smallest treated with tryptamine or cadaverine Fig. 3c) with half the number of embryos than females from the control. In females treated with amines, the abdomen usually contained mature embryos of a size comparable to embryos in females from the control sample, or slightly larger (the largest in the sample sprayed by tryptamine or cadaverine) (Table 2). The mean scores and standard error for the experiments integrated into Table 2 have been presented as the Supplementary Information Table S3.

\section{Effect of amines on survival and structures of the reproductive system of oviparous females of $C$. (C.) cupressi}

All applied amines affected the survival of oviparous females and caused a decrease in survival (Fig. 4). We observed the shortened longevity of oviparous females treated with amines compared to the controls. All females sprayed with water (controls) lived up to 8 days (mean $8.00 \pm 0.0$ days). The aphids that were sprayed with tryptamine lived between 1 and 7 days (mean $4.16 \pm 0.41$ days), and almost $52 \%$ of them lived less than 4 days. The females treated with putrescine lived from 1 to 6 days (mean $3.48 \pm 0.34$ days), and $64 \%$
Fig. 4 Effect of selected biogenic amines on oviparous females survival of $C$. $(C$.) cupressi $(n=25$ for each amine and control). Significant differences between all pairs of survival curves for putrescine: $\log$ rank test chi $^{2}=54.98, p<0.001$, cadaverine: log-rank test chi $^{2}=54.0, p<0.001$, tyramine: log-rank test $\mathrm{chi}^{2}=50.68$, $p<0.001$, tryptamine: log-rank test $\mathrm{chi}^{2}=55.0, p<0.001$

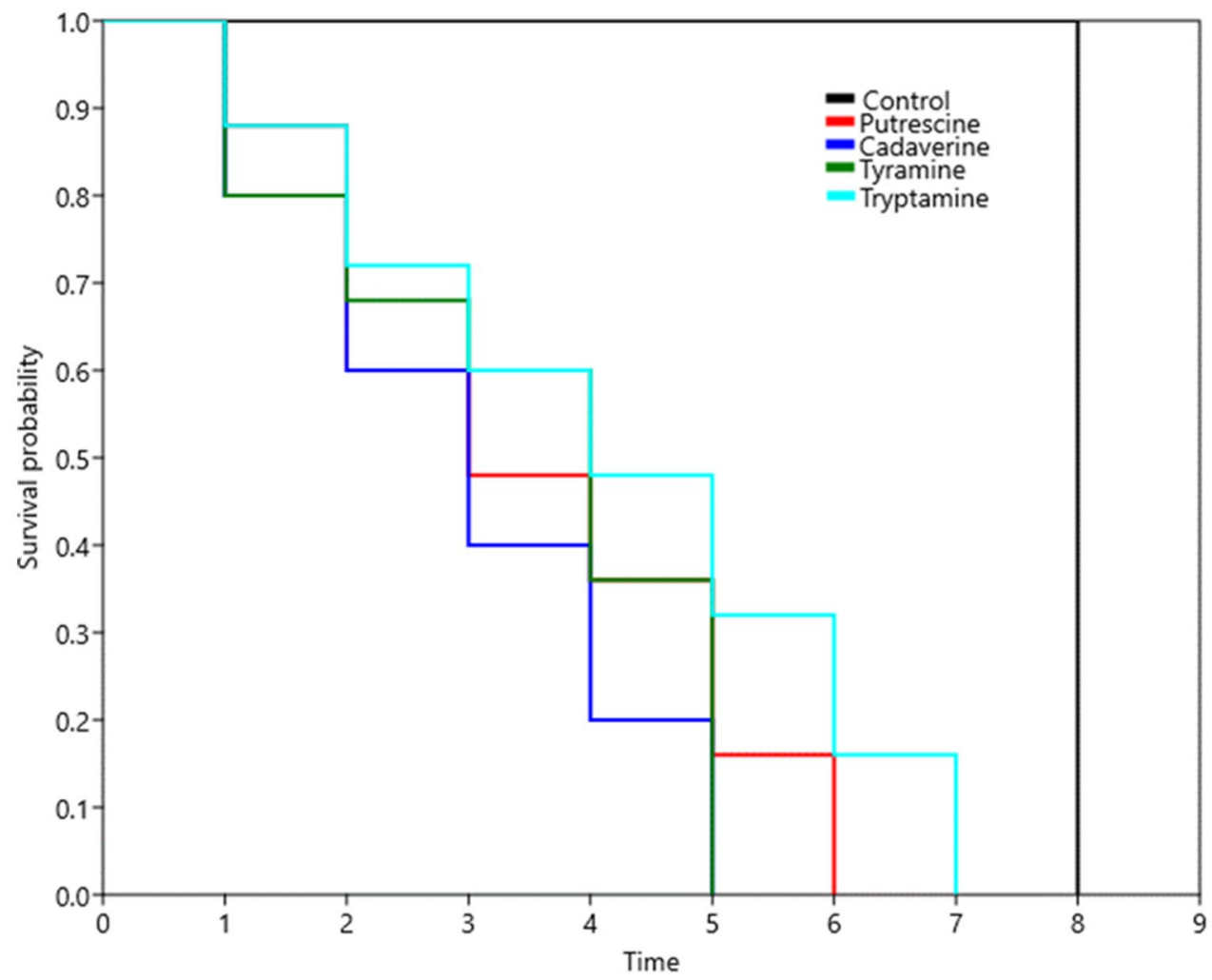


of females lived less than 4 days. Females' survival ranged between 1 and 5 days when females were sprayed with tyramine or cadaverine (mean $3.44 \pm 0.31$ days and mean $3.00 \pm 0.28$ days, respectively). If the oviparous females were treated with tyramine, almost $64 \%$ of aphids lived only 4 days, while $80 \%$ of females lived less than four days after using cadaverine. Effects of amines on oviparous females' survival confirmed a significant difference between all pairs of survival curves (log-rank test $\mathrm{chi}^{2}, p<0.001$ ) (Fig. 4).

The reproductive system of the adult oviparous female (control) tightly fills the abdomen. It is composed of paired ovaries and paired lateral oviducts that join to form a short common oviduct. The unpaired spermatheca and paired accessory glands are connected to a common oviduct. The ovaries are meroistic telotrophic and consist of six to seven ovarioles where each ovariole is composed of an inconspicuous terminal filament, a tropharium (trophic chamber), a vitellarium housing usually a growing oocyte, and a pedicel (ovariole stalk) (Fig. 5a). Apart from small differences in the size of developing ovarioles (the smallest in the oviparous females feeding on plants sprayed with tyramine or cadaverine), no significant differences in the morphology of the reproductive system were observed. However, in oviparous females treated with putrescine developing ovarioles were disproportionately small compared to other reproductive system structures (Fig. 5b). Oviparous females treated with biogenic amines were smaller (the smallest treated with tryptamine or tyramine) than females from the control group (Table 2, Supplementary Information Table S3, Fig. 3d).

\section{Discussion}

Aphids are specialized phloem sap feeders and an example of $r$-strategists (Bell et al. 2017). Individual viviparous female have extremely high growth and developmental rates, allowing populations to increase rapidly. The availability of food and its quality determines the lifespan and the fecundity of these insects. However, additional biotic and abiotic factors, especially the plant resistance, strongly influence demographic parameters of the aphid population (Leather et al. 2017).

Generally, our laboratory experiments showed that the used selected biogenic amines affect the development and demographic parameters of the cypress aphid population studied. To demonstrate these effects, we used the spring generation F1, which is characterized by the largest number of individuals in most aphid species (Dixon and Dharma 1980; Karley et al. 2004). Survival, development time, and fecundity, combined into a single statistic - the intrinsic rate of increase $\left(r_{\mathrm{m}}\right)$-decreased after using amines compared to the control, with the minimum value (0.01) in the population treated with tyramine or putrescine. The generation time $(T)$ was the longest in the population also treated with tyramine or putrescine. Similarly, the use of cadaverine prolonged the generation time and significantly extended the pre-reproduction period of the F1 generation (Table 1). Thus, all of these biogenic amines negatively affect the multiplication of the aphid population colonizing the host plant.

Our research also indicates that the use of biogenic amines resulted in a significant reduction in the total fecundity and the average daily fecundity both in the fundatrix (F0) and the fundatrigeniae (F1). The fecundity of the fundatrix (F0) decreased by half after spraying tyramine or putrescine, while in the F1 generation it halved after using tryptamine or tyramine. The influence of the amines tested on the fecundity was insignificant in the F5 generation, with the exception of the low impact of tyramine. In addition to selected viviparous generations, we also analyzed in our research the survival of oviparous females influenced by the biogenic amines. All amines used caused a decrease in survival of oviparous females-from the lowest impact if
Fig. 5 Gross morphology of the oviparous female reproductive system of $C$. (C.) cupressi a not sprayed with biogenic amines and $\mathbf{b}$ sprayed with putrescine. $a g$ accessory glands; co common oviduct; evo early vitellogenic oocyte; $s$ spermatheca; $t$ tropharium; $v o$ vitellogenic oocyte

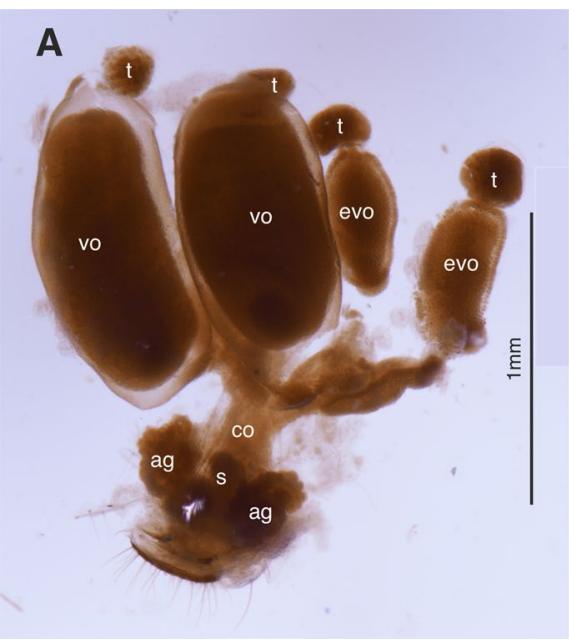

B

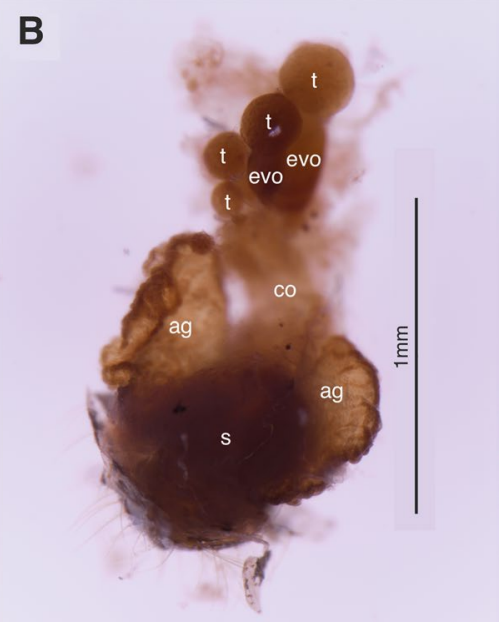


they were treated with tryptamine, where $52 \%$ of oviparous females lived less than 4 days, to the highest, using cadaverine, where $80 \%$ of females lived less than four days in comparison with the average lifespan of these morphs being eight days.

Former experiments with the use of EPG (electrical penetration graphs) indicated that the addition of selected biogenic amines (i.e., agmatine, cadaverine, putrescine, spermidine, spermine, or tyramine) to the artificial diet of the viviparous generation of the bird cherry-oat aphid (Rhopalosiphum padi $\mathrm{L}$.) clearly affected its probing behavior. In particular, the $10 \mathrm{mM}$ concentration of these amines, especially cadaverine, reduced or wholly inhibited aphid ingestion (Sempruch et al. 2016). Similarly, agmatine, cadaverine, putrescine, spermidine, or spermine at $0.1 \%$ concentration also reduced the quantity of assimilated food, body mass, and survival of the viviparous generation of the grain aphid (Sitobion avenae F.) (Sempruch et al. 2010). The concentration of amines was important in the conducted experiments. Optimal results were obtained using $10 \mathrm{mM}$ concentration of selected polyamines and aromatic amines, which is also confirmed by our research. At higher concentrations, these compounds may have cytotoxic properties (Sempruch et al. 2016), whereas lower concentrations did not significantly affect the demographic parameters of the aphid species tested (Sempruch et al. 2011).

In female insects, one of the body's responses to periodic starvation is oocyte resorption (Lim and Lee 1981; Soller et al. 1999; Rosenheim et al. 2000; Kotaki 2003). In the aphid species, Megoura viciae Buckton (Ward and Dixon 1982; Brough and Dixon 1990) or Acyrthosiphon pisum Harris (Soldan and Stary 1981) starvation led to resorption of the smallest embryos, whereas $S$. avenae tends to invest in the development of larger embryos at the expense of reducing the lifespan and future fecundity (Xu et al. 2019). In our experiments, the selected biogenic amines used influenced the number of developing embryos, which was especially visible in the F0 generation. In all parthenogenetic generations spraying host plants with cadaverine led to a significant reduction in the number of developing embryos. Moreover, among studied amines, cadaverine caused marked changes in the body length of viviparous generations F0, F1, and F5, compared to the control sample. In all parthenogenetic generations, the dissected female abdomen contained a greater number of mature embryos compared to control samples. Therefore, the biogenic amines used could disrupt the feeding behavior of aphids, leading to a short period of starvation, which influenced the number of embryos and, as a consequence, the fecundity of females. Although the use of biogenic amines did not significantly affect the number of eggs produced by oviparous females, it had an impact on their lifespan, in particular cadaverine. This polyamine contributes to plant growth and development, cell signaling, and insect defense (Jancewicz et al. 2016). Next to putrescine, spermidine and spermine are considered in plants as a candidate of the signal systems which are employed in the defense system against stress (Tomar et al. 2013).

The unique strategy of aphids is to adapt their life cycle to the seasonal changes in host plants, i.e., to avoid adverse trophic conditions in the middle of summer. Among others, these strategies include a higher fertility rate in the spring and autumn that is reduced in the summer (Wieczorek 2015). The cypress aphid, as a monoecious species, is a good example of implementing such a strategy. Therefore, combating these aphids should focus on the generation of stem mothers (F0) and their offspring (fundatrigeniae, F1). Our laboratory tests, dedicated to different generations of aphids, have confirmed that especially the first spring generations are the most sensitive to selected biogenic amines and seem to be the right target for using biopesticides, also based on biogenic amines. Similarly, the sexual generation, equally sensitive to the effects of selected biogenic amines, maybe a convenient target in the fight against these insects. This may be especially important in the temperate zone, where the overwintering egg is a form of surviving aphids. Therefore, in addition to combating spring generations, the elimination of the sexual generation may be key in plant protection practice. The Royal Horticultural Society (2004) recommends spraying biopesticides or chemical pesticides in early summer to prevent damage caused by the cypress aphid, which is consistent with our results of the influence of biogenic amines on its spring generation. Repeat spraying in early autumn, targeted at the sexual generation, should have a similar effect, further reducing the number of overwintering eggs laid. Thus, our results concerning the reproductive adaptation of the cypress aphid in response to biogenic amines can be used for effective pest management.

Our research has clearly shown that BAs do affect development and demographic parameters of aphids. However, the pesticides' toxicity to various species of insects reveal a direct relationship with the environmental temperature range (Boina et al. 2009; Glunt et al. 2018; Li et al. 2020). Caution must be exercised when drawing conclusions about a chemical's efficacy from laboratory assays performed at only one temperature, as phenotypic resistance can vary significantly even over a temperature range that could be experienced in the field during a single day (Glunt et al. 2018). In the cypress aphid, it is especially important as the population of this species occurs both in the temperate (our study, where the dedicated temperature $20{ }^{\circ} \mathrm{C}$ were tested) and warmer climate (e.g., African population). Thus, product based on amines for commercial use needs further studies, also in the context of the effects of temperature on the efficacy of amines interventions under various temperature conditions. 
Supplementary Information The online version contains supplementary material available at https://doi.org/10.1007/s11829-021-09839-z.

Acknowledgements This research was supported by the National Science Centre, Poland, Grant No. 2015/19/B/NZ9/01265. We are greatly indebted to Cezary Sempruch for introducing us to the research methodology regarding the influence of biogenic amines on the demographic parameters of aphids. We thank Richard Ashcroft for linguistic improvement of the manuscript. The authors are also grateful to the Editors and the four anonymous Reviewers for all valuable comments during the review process.

Author contributions Conceptualization: KW, RD, and PŚ; Methodology: KW, RD, and PŚ; Formal analysis and investigation: KW, RD, and PŚ; Writing — original draft preparation: KW and RD; Writing—review and editing: KW, RD, and PŚ; Funding acquisition: KW; Resources: KW, RD, and PŚ; Supervision: KW.

Funding This research was supported by the National Science Centre, Poland, Grant No. 2015/19/B/NZ9/01265.

\section{Declaration}

Conflict of interest The authors declare that they have no conflict of interest associated with this work.

Open Access This article is licensed under a Creative Commons Attribution 4.0 International License, which permits use, sharing, adaptation, distribution and reproduction in any medium or format, as long as you give appropriate credit to the original author(s) and the source, provide a link to the Creative Commons licence, and indicate if changes were made. The images or other third party material in this article are included in the article's Creative Commons licence, unless indicated otherwise in a credit line to the material. If material is not included in the article's Creative Commons licence and your intended use is not permitted by statutory regulation or exceeds the permitted use, you will need to obtain permission directly from the copyright holder. To view a copy of this licence, visit http://creativecommons.org/licenses/by/4.0/.

\section{References}

Alford DV (2012) Pests of ornamental trees, shrubs and flowers: a color handbook, 2nd edn. Academic Press, London

Alleck M, Seewooruthun SI, Ramlugun D (2006) Cypress aphid status in Mauritius and trial releases of Pauesia junioerorum (Hymenoptera: Braconidae) a promising biocontrol agent. Rev Agric Sucr Île Maurice 85(1/2/3):60-67

Bell JR, Pierre J-S, Dedryver C-A (2017) Aphid population dynamics: from fields to landscape. In: Van Emden F, Harrington $R$ (eds) Aphids as crop pests, 2nd edn. CABI Publishing, London, pp 280-303

Binazzi A (1978) Contributions to the knowledge of aphids on conifers I. The species of the genera Cinara Curt., Schizolachnus Mordv., Cedrobius Remaud. and Eulachnus D. Gu. present in Italy (Homoptera Aphidoidea Lachnidae). Redia 41:291-400

Blackman RL, Eastop VF (2020) Aphids of the world's plants: an online identification and information guide. http://www.aphid sonworldsplants.info. Accessed 26 May 2020

Boina DR, Onagbola EO, Salyani M, Stelinski LL (2009) Influence of posttreatment temperature on the toxicity of insecticides against
Diaphorina citri (Hemiptera: Psyllidae). J Econom Entomol 102:685-691. https://doi.org/10.1603/029.102.0229

Brough CN, Dixon AFG (1990) The effects of starvation on development and reproductive potential of apterous virginoparae of vetch aphid Megoura viciae. Entomol Exp Appl 55:41-45

CABI (2020) Cinara cupressi sensu lato. In: Invasive Species Compendium. Wallingford, UK: CAB International. www.cabi.org/isc Accessed 12 May 2020

Chen D, Shao Q, Yin L, Younis A, Zheng B (2019) Polyamine function in plants: metabolism, regulation on development, and roles in abiotic stress responses. Front Plant Sci 9:1945. https://doi.org/ 10.3389/fpls.2018.01945

Chilima CZ (1995) Cypress aphid control: first African release of Pauesia juniperorum. FRIM 74:2

Ciesla W (1991) The Cypress aphid, Cinara cupressi (Buckton) in Africa. In: Exotic aphid pests of conifers: a crisis in African forestry. FAO (Food and Agriculture Organization), Kenia, p 160

Day KR, Kario MT, Abraham YJ, Kfir R, Murphy ST, Mutitu K, Chilima CZ (2003) Chapter 7: Homopteran pests of conifers in Africa. In: Neuenschwander P (ed) Biological control in IPM systems in Africa. CAB International, Wallingford, pp 101-112

Demeke AD (2018) Status of cypress aphid on Cupressus lusitanica and Juniperus procera in protected and cultivated forests of South Wollo, Ethiopia. J For Res 31:333-337. https://doi.org/ 10.1007/s11676-018-0819-y

Dixon AFG, Dharma TR (1980) Number of ovarioles and fecundity in the black bean aphis Aphis fabae. Entomol Exp Appl 28(1):1-14. https://doi.org/10.1111/j.1570-7458.1980.tb029 81. $\mathrm{x}$

Dransfield R, Brightwell R (2020) Cinara cupresii, cypress aphid. https://influentialpoints.com/Gallery/Cinara_cupressi_cypress_ aphid.htm. Accessed 2 Jun 2020

Durak R, Durak T (2015) Redescription of males of the aphid species Cinara (Cupressobium) tujafilina and Cinara (Cupressobium) cupressi (Hemiptera, Lachninae). Zootaxa 4032(2):209-214

Durak R, Borowiak-Sobkowiak B, Socha M (2007) Bionomy and ecology of Cinara cupressi (Buckton, 1881) (Hemiptera, Aphidoidea). Pol J Entomol 76(2):107-113

FAO (2009) Cinara cupressivora. Forest pest species profile. http:// www.fao.org/forestry/13557-011835cf4f2791802c40723e174bd9 9d.pdf. Accessed 12 May 2020

Favret C (2020) Aphid species file. Version 5.0/5.0. http://Aphid.Speci esFile.org. Accessed 26 May 2020

Global Invasive Species Database (GISD) (2020) Species profile Cinara cupressi. http://www.iucngisd.org/gisd/species.php?sc= 121. Accessed 12 May 2020

Glunt KD, Oliver SV, Hunt RH, Paaijmans KP (2018) The impact of temperature on insecticide toxicity against the malaria vectors Anopheles arabiensis and Anopheles funestus. J Malar. https:// doi.org/10.1186/s12936-018-2250-4

González P, Ide S, Jaques L, Peralta M, Rojas E (2008) Programa de control biológico de Cinara cupressi Buckton (Hem: Aphididae), Proyecto FDI-CORFO. Manejo Integrado: Técnica para la conservación y recuperación del crecimiento de Austrocedrus chilensis. Chile. p 26.

Hammer Ø, Harper DAT, Ryan PD (2001) Past: paleontological statistics software package for education and data analysis. Palaeontol Electron 4(1/4):1-9. http://palaeo-electronica.org/2001_1/past/ issue1_01.htm.

Hennion F, Litrico I, Bartish IV, Weigelt A, Bouchereau A, Prinzing A (2016) Ecologically diverse and distinct neighbourhoods trigger persistent phenotypic consequences, and amine metabolic profiling detects them. J Ecol 104(1):25-137

Jancewicz AL, Gibbs NM, Masson PH (2016) Cadaverine's functional role in plant development and environmental response. Front Plant Sci 7:870. https://doi.org/10.3389/fpls.2016.00870 
Kairo MTK, Murphy ST (1999) Temperature and plant nutrient effects on the development, survival and reproduction of Cinara sp. nov., an invasive pest of cypress trees in Africa. Entomol Exp Appl 92:147-156

Kairo MT, Murphy ST (2005) Comparative studies on populations of Pauesia juniperorum (Hymenoptera: Braconidae), a biological control agent for Cinara cupressivora (Hemiptera: Aphididae). Bull Entomol Res 95:597-603

Karley AJ, Parker WE, Pitchford JW, Douglas AE (2004) The midseason crash in aphid populations: why and how does it occur? Ecol Entomol 29(4):383-388. https://doi.org/10.1111/j.03076946.2004.00624.x

Kotaki T (2003) Oosorption in the stink bug, Plautia crossota stali: induction and vitellogenin dynamics. J Insect Physiol 49:105-113

Leather SR, Awmack SA, Garrat MPD (2017) Growth and development. In: Van Emden F, Harrington R (eds) Aphids as crop pests, 2nd edn. CABI Publishing, London, pp 98-114

Leszczyński B, Wright L, Bakowski T (1989) Effect of secondary plant substances on winter wheat resistance to grain aphid. Entomol Exp Appl 52:135-140

Li Y, Dou Y, An J, Tu X, Lv H, Pan W, Dang Z, Gao Z (2020) Temperature-dependent variations in toxicity of diamide insecticides against three lepidopteran insects. Ecotoxicology 29(5):607-612. https://doi.org/10.1007/s10646-020-02181-9

Lim SJ, Lee SS (1981) The effect of starvation on haemolymph metabolites, fat body and ovarian development in Oxya japonica (Acrididae: Orthoptera). J Insect Physiol 27:93-96

Lowe S, Browne M, Boudjelas S, De Poorter M (2000) 100 of the world's worst invasive alien species: a selection from the global invasive species database. The Invasive Species Specialist Group (ISSG), Auckland, p 12

Mills N (1990) Biological control of forest aphid pests in Africa. Bull Entomol Res. https://doi.org/10.1017/S0007485300045880

Missanjo E, Kamanga-Thole G (2015) A retrospective study of Cinara cupressivora damage on Cupressus lusitanica clonal seed orchard in Malawi between 1997 and 2003. Adv Res 5(1):1-7. https://doi. org/10.9734/AIR/2015/18609

Montalva C, Rojas E, Ruiz C, Lanfranco D (2010) The cypress aphid in Chile: A review of the current situation and preliminary data of the biological control. Bosque 31(2):81-88

Montalva C, Rojas E, Barta M, Lanfranco D (2013) Biological control agents of cypress aphid present in Chile. In: Conference paper 4 international symposium on biological control of arthropods. Púcon, Chile. http://doi.org/https://doi.org/10.13140/2.1.1540. 8649

Mustafa TM (1987) Reproductive biology and population studies of the cypress aphid, Cinara cupressi (Buckton) and pine aphid, $C$. maritime (Dafour). Dirasat 14:99-105

Pereira JAM, Porto-Figueira P, Andrade B, Gonçalves P, Pataca J, Câmara JS (2018) Biogenic amines in food: occurrence and analytical challenges for their analysis. In: Studnik J (ed) Biogenic Amines (BA): origins, biological importance and human health implications. Nova Science Publishers, Inc., New York, pp 1-25
Remaudière G, Binazzi A (2003) Les Cinara du Pakistan II. Le sousgenre Cupressobium (Hemiptera, Aphododae, Lachninae). Rev Fr Entomol 25(2):85-96

Rosenheim JA, Heimpel GE, Mangel M (2000) Egg maturation, egg resorption and the costliness of transient egg limitation in insects. Proc R Soc B 267(1452):1565-1573. https://doi.org/10.1098/rspb. 2000.1179

Royal Horticultural Association (2004) Cypress aphid. https://www. rhs.org.uk/advice/profile?pid=492. Accessed 12 May 2020

Sempruch C, Leszczyński B, Kozik A, Chrzanowski G (2010) The influence of selected plant polyamines on feeding and survival of grain aphid (Sitobion avenae F.). Pesticides 1-4:15-20

Sempruch C, Osiński P, Leszczyński B (2011) Wpływ wybranych amin roślinnych na zasiedlanie liści pszenżyta ozimego przez mszycę czeremchowo-zbożowa. Prog Plant Prot 51:427-430

Sempruch C, Marczuk W, Leszczyński B, Czerniewicz P (2013) Participation of amino acid decarboxylases in biochemical interactions between triticale (Triticosecale; Poaceae) and bird cherryoat aphid (Rhopalosiphum padi; Aphididae). Biochem Syst Ecol 51:349-356

Sempruch C, Leszczyński B, Wilczewska M, Sytykiewicz H, Czerniewicz P, Goławska S, Chrzanowski G, Matok H (2016) Influence of selected plant amines on probing and feeding behaviour of bird cherry-oat aphid (Rhopalosiphum padi L.). Bull Entomol Res 106(3):368-377. https://doi.org/10.1017/S0007485316000055

Soldan T, Stary P (1981) Parasitogenic effects of Aphidius smithi (Hymenoptera: Aphidiidae) on the reproductive organs of the pea aphid, Acyrthosiphom pisum. Acta Entomol Bohemoslov 78:243-253

Soller M, Bownes M, Kubli E (1999) Control of oocyte maturation in sexually mature Drosophila females. Dev Biol 208:337-351

TIBCO Software Inc. (2017) Statistica (data analysis software system), version 13. http://statistica.io

Tomar PC, Lakra N, Mishra SN (2013) Cadaverine: a lysine catabolite involved in plant growth and development. Plant Signal Behav. https://doi.org/10.4161/psb.25850

Ward SA, Dixon AFG (1982) Selective resorption of aphid embryos and habitat changes relative to life-span. J Anim Ecol 51:859-864

Wieczorek K (2015) Sexuales of aphids (Insecta, Hemiptera, Aphididae) - an alternative target in the pest control. Entomol Ornithol Herpetol 5:1. https://doi.org/10.4172/2161-0983.1000e115

Wyatt IJ, White PF (1977) Simple estimation of intrinsic increase rates for aphids and tetranychid mites. J Appl Entomol 14:757-766

Xu X, Lv N, Shi Q, Hu X, Wu J (2019) Reproductive adaptation in alate adult morphs of the English grain aphid Sitobion avenae under starvation stress. Sci Rep 9:2023. https://doi.org/10.1038/ s41598-019-38589-5

Publisher's Note Springer Nature remains neutral with regard to jurisdictional claims in published maps and institutional affiliations. 